\title{
Why Do Consumers Review Doctors Online? Topic Modeling Analysis of Positive and Negative Reviews on an Online Health Community in China
}

\author{
Patrick Cheong-Iao Pang \\ The University of Melbourne \\ mail@patrickpang.net
}

\begin{abstract}
Consumers often learn from others through a social learning process (e.g. electronic word of mouth) before making decisions. From the e-business perspective, online reviews have changed how people select products and services, and no doubt it is the same in the e-health sector. In this study, we examine online reviews of patients and health consumers for their doctors in an online health consultation platform in China. We combine machine learning and qualitative techniques to derive the themes of online reviews and the factors leading to positive and negative reviews. Our analysis demonstrates that service levels of hospitals, doctors' communication skills and their professional skills influence the sentiment of reviews. Our findings offer important insights into theories and practice for studying online reviews in the healthcare context.
\end{abstract}

\section{Introduction}

Information sharing has been an important area of Information Systems (IS) research for nearly two decades $[1,26,37,39]$. Individuals observe the referrals and shared information (e.g. product reviews) from others before they make decisions. Consistent with this strong focus on information cascades in industry, research has shown repeated evidence that users tend to mimic other's choices. To this end, a sizable body of research in IS have emerged over the last decade, attempting to identify and examine which type of information sharing is more influential in shaping subsequent user decisions and choices in an online community [16, 25, 32, 55].

Given the increasing proliferation of the Internet, individuals from diverse organizational, national, and cultural backgrounds can easily exchange information with others in an online community [39, 49, 57]. Trusov, Bucklin and Pauwels [53] have reported that usergenerated content on social media is seen as a reliable and valuable asset that has a significant influence on decision-making. Some researchers have associated these behaviors with electronic word of mouth (eWOM)

\author{
Libo Liu \\ Swinburne University of Technology \\ liboliu@swin.edu.au
}

and explained it from a motivational perspective with an emphasis on perceived benefits and costs [10, 15, 23].

Due to recent technological development, online health communities (OHCs) have become a popular option in China for addressing health needs. Health service consumers, which includes patients and other potential users accessing healthcare services [38], are able to use OHCs to consult with doctors and interact with other consumers. Many OHCs also allow users to rate their doctors and submit reviews. Online reviews on OHCs are a new type of eWOM [34]. It is different from other types of online communities because the communication and the knowledge sharing on OHCs require specific context and knowledge about specific medical conditions to interpret other's opinions [30]. In addition, research has shown that patients and consumers have complicated needs [42, 45]. These distinctions can make OHCs a different environment in terms of information sharing. To understand consumer behavior specifically in OHCs, we formulate our first research question as follows:

R1: Who health service consumers are the primary content creators in OHCs?

The extant literature has largely focused on eWOM, however, there are fewer studies investigating the behavior related to negative information in the OHCs context. Given the differences in OHCs and the consequences of negative treatment outcomes, individuals may act differently when they read negative reviews in OHCs. Therefore, the underlying mechanism of negative $\mathrm{OHC}$ reviews may be different from the current knowledge of information sharing and eWOM. This remains a research gap that needs further investigation. In this study, we classify reviews into two types, i.e. positive and negative reviews, in order to explore our second research question:

R2: Which health service factors are associated with positive/negative reviews in OHCs?

We collected 11,264 online reviews from the Good Doctor Online website (haodf.com), one of the largest $\mathrm{OHC}$ in China. These reviews were inputted into a topic modeling algorithm, which is a type of machine learning techniques for clustering data into several groups of relevant topics. Then, we used thematic analysis to 
derive themes from the reviews and applied grounded theory methodology to inform our model.

Our findings show that not only patients but also a wide variety of health consumers, such as family members, review their doctors in OHCs. As informed by our analysis, service levels of hospitals, doctors' communication skills and their professional skills can lead to positive reviews, whereas only communication skills and professional skills can lead to negative reviews. The main contributions of this study include a better understanding of the information sharing behaviors in OHCs from a content creator perspective and the themes emerged from $\mathrm{OHC}$ reviews. More specifically, we have (1) identified who are the main content creators of ratings and comments in OHCs, and (2) determined which health service factors are commonly associated with positive and negative reviews in OHCs. We investigated users' main concerns with clinical practice in $\mathrm{OHC}$ and developed a theoretical model that captures the factors and the intermediate sentiments.

\section{Related Work}

In this section, we present the heterogeneous literature supporting this study. In addition to presenting recent work about online reviews and $\mathrm{OHCs}$, we give a brief overview of topic modeling and explain how it is applicable to the current study.

\subsection{Online Review}

Online reviewing is a form of interpersonal communication among users concerning their personal experience about products or services in the online context [52]. There are two types of online reviews according to their emotional directions: positive reviews and negative reviews. Positive reviews share consumers' satisfactory experience towards products or services, whereas negative reviews express the dissatisfactory experience in an online context. The relationship between online reviews and user satisfaction is well explored in e-business literature [11, $46,47]$. The volume of online reviews is found significantly affecting users' decision marking [2]. In the domain of the movie industry, Lee, Hosanagar and Tan [32] have documented a more robust conformity phenomenon in friend relationships. That is, relative to prior ratings by strangers, friends' ratings always induce herding regardless of the popularity of the movie itself. Most recently, with a quasi-experimental design, Wang, Zhang and Hann [56] showed that rating similarity between friends was significantly higher after the friend relationship was established, indicating that users' previous ratings could exert social influence on their friends even beyond the taste similarity among them (i.e. the homophily effect). As a result of the knowledge capital possessed by opinion leaders, Iyengar, Van den Bulte and Valente [25] have found that the better connected adopters (i.e. opinion leaders) exert more influence on new product diffusion than do less connected ones even after controlling for marketing effort and arbitrary system wide changes. Similarly, van Eck, Jager and Leeflang [17] have demonstrated that opinion leaders are less susceptible to norms and more innovative, which subsequently facilitate the adoption process of new products. In the context of the choices of physician's prescriptions, Nair, Manchanda and Bhatia [14] suggest that physician's prescription behavior is significantly influenced by leading specialists. The above work clearly shows that the reviews and the behavior of other people can affect decision-making, including health-related decisions.

\subsection{Online Health Communities}

In the current study, we focus on the online reviews (more specifically, positive and negative reviews) obtained from $\mathrm{OHC}$ platforms. Researchers have found that people using OHCs consider creditability as an important issue and wish to get reliable advice from OHCs [30, 33, 43]. Previous literature takes a motivational perspective with an emphasis on perceived benefits and perceived costs to discuss information sharing to online communities [9, 18] and OHCs [59]. Similar to the reviews of other products, patients share their experience in OHCs and such shared information is influential in other people in the community [8, 61]. Recent work also has investigated $\mathrm{OHC}$ reviews and found that patients care about the qualities of clinicians [35], treatment effects [21], attitudes [21, 34], and technical skills [21, 22, 34]. Additionally, doctors' ratings in $\mathrm{OHCs}$ are important for them to gain establish reputation [12] and improve their services [60]. While this series of research has studied OHCs, little has a focus on the classification of reviews and the factors demonstrated in different classifications. This is a gap that we would like to address in this study.

\subsection{Topic Modeling Analysis in IS}

Topic modeling refers to a set of unsupervised machine learning algorithms for identifying topics (also known as thematic structures) in unstructured text [5]. With the unsupervised property, researchers do not need to define topics in advance to use topic modeling. As a branch of text mining techniques, topic modeling has diverse applications in health research, and has recently 
been used in IS studies [31]. Examples include categorizing themes of the comments of social media users [4, 27] and analyzing policy documents [19]. Recent work in Healthcare IS uses topic modeling to extract concepts from electronic health records $[3,41]$, and analyze online reviews and user comments [21, 22].

Among all topic modeling algorithms, Latent Dirichlet Allocation (LDA) is a probabilistic model from topic modeling [6] used by many researchers. Literature has suggested that LDA is an effective model for discovering topics [24]. As such, we adopt topic modeling for a first-pass analysis in this work to identify topics. This not only allows for analyzing a large quantity of data but has the potential to identify topics that we would not have noticed with manual inspection.

\section{Research Design}

In this section, we detail our data collection, data processing steps and how we apply machine learning and qualitative techniques to analyze the data.

\subsection{Data Collection}

We collected data from Good Doctor Online (haodf.com), one of the most popular OHC platform in China. To get this access to this data, we have collaborated with the web administrators of this $\mathrm{OHC}$ platform who have agreed to share the data in return for providing insights about the sentiment of the positive and negative reviews. Furthermore, we have received ethics clearance from our respective universities before proceeding to the data collection.

According to a report from Alexa.com, Good Doctor Online had a traffic rank of 916 in China as of February 2019. The daily number of visitors was over 3 million and the daily number of online consultations was approximately 300,000 . More than 580,000 doctors from 9,379 registered hospitals in China enrolled in this website as of Dec 2018. Over 200,000 among these doctors further provided telehealth consultation service via the online platform. Each doctor can create a personal profile on Good Doctor Online. On the personal profile, most doctors disclose their information and working experience. Figure 1 shows an example of a doctor's online profile.

In addition to these personal statements, doctors can receive feedback from the users on this platform. They can provide ratings as well as text-based reviews to doctors after consultation. Figure 2 illustrates a doctor's ratings and comments received in Good Doctor Online.

We sampled the doctors who had registered in Jiangsu Province from the website. For each doctor in the sample, we collected their profile information and their online reviews. As listed on the website, there were four self-reported levels of satisfaction associated with the reviews (i.e. unsatisfactory, normal, satisfactory and very satisfactory). These values were used as our basis to differentiate positive and negative reviews. To ensure that the sample included both positive and negative reviews, we randomly selected reviews from all satisfaction levels. The resulting sample consisted of 11,264 online reviews.

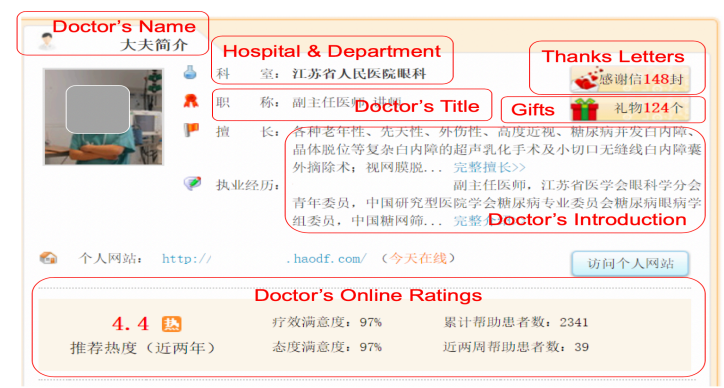

Figure 1. The illustration of a doctor's profile

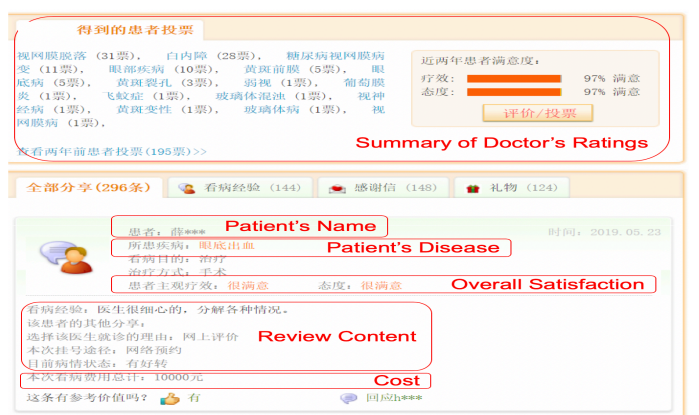

Figure 2. The screenshot of a patient's review

\subsection{Data Processing}

Reviews needed to be pre-processed and cleansed before analysis. We extracted the text content from the reviews and used Jieba (version 0.39) which is a popular Chinese tokenization library to segment the content into words. Stopwords, referring to meaningless and contentless words, were removed as common practice for processing data in recent IS research $[14,36]$. Additionally, doctors' names, titles and positions were removed because such information was not useful for deriving the actual topics of the reviews but introducing noise in our analysis. Finally, reviews with duplicated content were removed. This left us with 10,870 reviews for subsequent analysis.

\subsection{Topic Modeling and Qualitative Analysis}

The processed data was inputted to the LDA topic modeling algorithm for further analysis. The algorithm acted as the preliminary screening tool for us to process 
a large scale of data. We used a commonly used machine learning implementation in Python called scikit-learn (version 0.20.3) [48] in this study. LDA requires researchers to specify how many topics the algorithm should return and deciding this number is still an open problem. Other IS research use an experimental approach to determine this number by testing different parameters and then choose the number that is most meaningful to the researchers [29, 36]. Both authors agreed that 6 topics could produce the best output after testing topic numbers ranging from 5 to 20 .

Previous literature suggested that human intervention could further improve the interpretation of the topics returned by the LDA algorithm. The raw topic modeling output contains only a list of keywords associated with each topic. Oftentimes this information may not be enough for researchers to understand the topic. In line with other similar research [14, 29], we manually assign a label for each topic to briefly describe the meaning of that topic, by reading 20 reviews within that topic. This labeling step enriches the results and is crucial for successive data analysis.

In addition to machine learning, we employed a qualitative methodology to analyze the data. Following the IS guidelines of formulating theories from empirical data $[54,58]$, we used the grounded theory methodology [50] to create our model. The topic modeling results served as the basis of the initial version of the model. Then, we selected 20 reviews from each topic and applied thematic analysis [7] to derive high-level themes, which were used to update the model. This process was performed iteratively until no further updates could be made to the model (i.e. reached saturation) [51]. The model formulation process was reviewed by another researcher and both authors have agreed on the final version of the model.

\section{Results}

In this section, we present the results of our topic modeling analysis grouped by each satisfactory level, i.e. unsatisfactory, normal, satisfactory and very satisfactory respectively. Table 1 lists the number of reviews included in each satisfaction level.

Table 1. The numbers of reviews at different satisfaction level

\begin{tabular}{|l|r|r|}
\hline Level & Count & Percentage \\
\hline Unsatisfactory Reviews & 839 & $8 \%$ \\
\hline Normal Reviews & 320 & $3 \%$ \\
\hline Satisfactory Reviews & 4,108 & $38 \%$ \\
\hline Very Satisfactory Reviews & 5,603 & $52 \%$ \\
\hline Total & 10,870 & $100 \%$ \\
\hline
\end{tabular}

\subsection{Unsatisfactory Reviews}

Table 2 lists the topics identified in the unsatisfactory reviews. The areas covered by these topics include the problems and the unsatisfactory outcomes of treatments (U1, U2), the low skill level of doctors (U3), and the ineffective communication among patients, families and doctors (U4, U5, U6). People commonly reported that doctors had a hostile attitude towards patients and their families. In addition, there is a topic (U2) that clustered comments about children, which shows people's consistent concerns in regard to pediatricians. As shown in the table, the overall tone of these topics was relatively negative.

Table 2. Topics of unsatisfactory reviews

\begin{tabular}{|l|l|r|}
\hline ID & Label & Count \\
\hline U1 & $\begin{array}{l}\text { Unsatisfactory outcomes after } \\
\text { operations/treatments }\end{array}$ & 228 \\
\hline U2 & $\begin{array}{l}\text { Inaccurate diagnoses and incorrect } \\
\text { treatments related to children }\end{array}$ & 126 \\
\hline U3 & Doctors with insufficient skill level & 28 \\
\hline U4 & Not respecting patients & 21 \\
\hline U5 & Bad communication with patients & 237 \\
\hline U6 & Bad attitude to families & 199 \\
\hline
\end{tabular}

Below list some representative quotes in this type of reviews. These selected reviews were translated from Chinese to English by a bilingual researcher for the purpose of giving examples, and the topics and record identifiers were given at the end of each quote.

- My mother died the next day after surgery, and I can't accept this until now. If the pre-operation evaluation could be more cautious, and if there was no major bleeding during the operation, my mother might be able to recover. - Topic U1, Record 816

- ... My baby was 8-month old, vomiting, and prescribed oral rehydration salts. ... I got home and found that the instructions read "generally not for premature babies" and my baby was a premature one. The doctor did not ask and prescribed this medicine... - Topic U2, Record 339

- I did not like her. (The doctor) did not respect reasonable requests from patients, and ignore (the requests) directly - Topic U4, Record 669

- His attitude toward patients was very bad. My baby was 8-month old. He was very fierce and said "stop crying". He casually asked about the condition and prescribed. Very impatient and not allowing to ask more questions. - Topic U6, Record 298

\subsection{Normal Reviews}

Table 3 shows the topics of the reviews at the normal 
level. Unlike unsatisfactory reviews, this category of reviews included positive, neutral and negative topics. Consumers reported good service and attitude (N2, N3, N4), but sometimes the treatment did not work as expected (N3, N5). We could still observe some reviews complaining about treatment issues, as well as the impatience and the unfriendliness of doctors (N1, N6). Again, like unsatisfactory reviews, there is one specific topic (N4) in which the patients were children.

Table 3. Topics of normal reviews

\begin{tabular}{|l|l|r|}
\hline ID & Label & Count \\
\hline N1 & Incorrect treatment plan & 95 \\
\hline N2 & Doctors' patience and carefulness & 26 \\
\hline N3 & $\begin{array}{l}\text { Good service but no improvement in } \\
\text { health }\end{array}$ & 10 \\
\hline N4 & $\begin{array}{l}\text { Good service and communication } \\
\text { (related to children) }\end{array}$ & 63 \\
\hline N5 & $\begin{array}{l}\text { Treatment with no effect and having } \\
\text { a relapse }\end{array}$ & 75 \\
\hline N6 & Impatient and unfriendly & 51 \\
\hline
\end{tabular}

The following are the quotations for the topics in this group of reviews.

- Passionate in explaining and helping patients to analyze (their conditions). Reminded them to pay attention to lifestyle and medications... - Topic N2, Record 150

- It is impressive that the (doctor's) attitude was very good. Maybe I was not lucky enough, still no improvement (in my condition). - Topic N3, Record 127

- My child is 4-year-old and has an allergy to mites. No improvement so far, but I will continue to use the medicine... - Topic N4, Record 177

- The prescription might not be right. There was no effect after medication. However Dr. Zhu was very responsible and had a good attitude... - Topic N5, Record 125

- Online reviews were not trustworthy. Reviews said (the doctor) was patient and had a good attitude. There were no such things. I went to (the doctor) and waited for 8 hours, but (the doctor) sent us away after saying almost ten sentences. - Topic N6, Record 39

\subsection{Satisfactory Reviews}

Table 4 shows the topics of satisfactory reviews. Positive topics emerged from this group of reviews, for example, good services (S1), patience (S2) and improved health conditions (S3). Topic S5 contained reviews suggesting that the doctors had a high level of skills. In addition, consumers started to express their gratitude to clinicians (S4) at this satisfactory level.

Table 4. Topics of satisfactory reviews

\begin{tabular}{|l|l|r|}
\hline ID & Label & Count \\
\hline S1 & Good attitude and service & 693 \\
\hline S2 & $\begin{array}{l}\text { Good communication, patience and } \\
\text { carefulness }\end{array}$ & 776 \\
\hline S3 & Condition improved & 646 \\
\hline S4 & Appreciation (for treating children) & 591 \\
\hline S5 & High level of skills & 1,117 \\
\hline S6 & $\begin{array}{l}\text { In the progress of treatment (result } \\
\text { unknown yet) }\end{array}$ & 285 \\
\hline
\end{tabular}

The following quotes were selected from the group of satisfactory reviews.

- (The doctor was) friendly and gentle. (The doctor) patiently listened to the patient's requests and promptly responded to their enquiries. - Topic S2, Record 1680

- Director Wang was responsible and analyzed the conditions carefully and meticulously. The condition improved significantly after treatment. Topic S3, Record 1847

- I sincerely thank the doctor for the meticulous treatment for my family. Here express my gratitude again. - Topic S4, Record 312

- After three times of Chinese medicine treatments, I haven't improved much yet. I will follow the doctor's advice and insist on taking the medicine and hoping to achieve the desired results. - Topic 6 , Record 448

\subsection{Very Satisfactory Reviews}

Table 5 displays the analysis of very satisfactory reviews. The topics in this category consisted of the outcomes of treatments (V1, V3), the knowledge skills of doctors (V5), their attitudes (V2, V6), as well as the communication with clinicians (V4). We observed that two topics were particularly related to the experience with kids and babies. The sentiment of these topics was overwhelmingly positive.

Table 5. Topic labels of very satisfactory reviews

\begin{tabular}{|l|l|r|}
\hline ID & Label & Count \\
\hline V1 & $\begin{array}{l}\text { Improvement in children's } \\
\text { conditions }\end{array}$ & 985 \\
\hline V2 & $\begin{array}{l}\text { Patient and professional (for treating } \\
\text { babies) }\end{array}$ & 739 \\
\hline V3 & $\begin{array}{l}\text { Positive outcomes after operations; } \\
\text { showing appreciation }\end{array}$ & 1,001 \\
\hline
\end{tabular}




\begin{tabular}{|l|l|r|}
\hline V4 & Good caring and good explanation & 1,515 \\
\hline V5 & High level of skills & 973 \\
\hline V6 & $\begin{array}{l}\text { Friendliness, encouraging and taking } \\
\text { up responsibilities }\end{array}$ & 390 \\
\hline
\end{tabular}

The following quotes were selected from the group of very satisfactory reviews.

- The doctor's attitude was very good and the opinions were pertinent. The child's condition had improved! - Topic V1, Record 364

- Dr. Cui was the most patient doctor I had ever seen. My baby was crying when seeing the doctor. Dr. Cui stayed patiently until the crying stopped before starting the consultation. - Topic V2, Record 5343

- Excellent medical skills, meticulous patience, detailed explanation, sincere and friendly. (The doctor) is a role model... - Topic V4, Record 5502

- Excellent medical skills and enthusiastic. Firstclass service and treating patients like their loved ones... - Topic V5, Record 3781

- Thanks to Director He. He was gentle and responsible for patients. He often encouraged us. Thank you. - Topic V6, Record 845

\section{Discussion}

In this section, we firstly highlight the participation from different types of health consumers, followed by the explanation of the themes. Finally, we propose a model with both positive and negative reviews.

\subsection{Reviewers Are Not Just Patients}

It has been observed that not only patients comment on doctors but also their parents and families. In line with other research, we refer these non-patients as health consumers, which means the potential users of the healthcare system [38]. The results reassure our proposition that OHCs are used by the full spectrum of consumers, rather than patients only. In addition, our findings are consistent with previous literature that people acts on behalf of their loved ones and friends in addition to themselves in the health context $[42,44]$. As such, $\mathrm{OHC}$ websites are knowledge exchange and information sharing platforms for a diverse group of users, therefore we propose that researchers have to aware the existence of non-patient health consumers, and design their studies accordingly, when review data are sought from OHCs. Also, OHC system designers and facilitators have to be aware of the potential use by both patients and consumers.

We argue that the clinical consultations experienced by family members (e.g. children), who often are not the patients themselves, are the key topics for which health service consumers write online reviews. This is demonstrated by the fact that a number of topics (e.g. $\mathrm{U} 2, \mathrm{U} 6, \mathrm{~N} 4, \mathrm{~S} 4$ and V2) are explicitly linked to keywords such as "babies", "children", "family". In these cases, the review content reflects the sentiment and opinions of such users, instead of the ones directly from patients. This finding is similar to the one of Hao and Zhang [21]. From the knowledge sharing perspective, such non-patient reviews do not truly reflect the feelings and thoughts about the consultations and treatments, but these reviews affect how other patients and consumers select healthcare services and their decision-making.

\subsection{Themes of Doctors' Reviews}

Table 6 gives an overview of themes and the topics associated with each of these themes. In the following paragraphs, we further elaborate on these themes and categories.

Table 6. Themes identified in all topics

\begin{tabular}{|c|c|c|}
\hline Theme & $\begin{array}{r}\text { No. of } \\
\text { Topics }\end{array}$ & $\begin{array}{l}\text { Related } \\
\text { Topic IDs }\end{array}$ \\
\hline \multicolumn{3}{|l|}{ Hospital Level } \\
\hline Administrative Service & 3 & $\mathrm{~S} 1, \mathrm{~N} 3, \mathrm{~N} 4$ \\
\hline \multicolumn{3}{|l|}{ Communication Skills } \\
\hline Communication & 4 & $\begin{array}{l}\text { S2, V4, N4, } \\
\text { N5 }\end{array}$ \\
\hline $\begin{array}{l}\text { Attitude, e.g. patience } \\
\text { and friendliness }\end{array}$ & 8 & $\begin{array}{l}\text { S1, S2, V2, } \\
\text { V6, N2, N6, } \\
\text { U4, U6 }\end{array}$ \\
\hline \multicolumn{3}{|l|}{ Professional Skills } \\
\hline $\begin{array}{l}\text { Health Outcome, e.g. } \\
\text { changes in conditions }\end{array}$ & 6 & $\begin{array}{l}\text { S3, V1, V3, } \\
\text { N3, N5, U1 }\end{array}$ \\
\hline Skill Set & 3 & S5, V5, U3 \\
\hline $\begin{array}{l}\text { Treatment, e.g. medicine } \\
\text { and operations }\end{array}$ & 6 & $\begin{array}{l}\text { S6, V3, N1, } \\
\text { N5, U1, U2 }\end{array}$ \\
\hline
\end{tabular}

Based on the topics derived from our data, we have summarized these topics into six themes that can represent the overall picture of the online reviews. These six themes were grouped into three categories, which represent the experience of patients and consumers in different areas, such as the service from the hospitals, doctors' communication skills and their professional capabilities. These findings respond to our first research question R1.

5.2.1 Hospital Level. This category includes a theme related to hospitals or healthcare providers. Administrative Service is the theme that covers many aspects of the administrative operations in hospitals, for example, registration, dispensary, waiting time, 


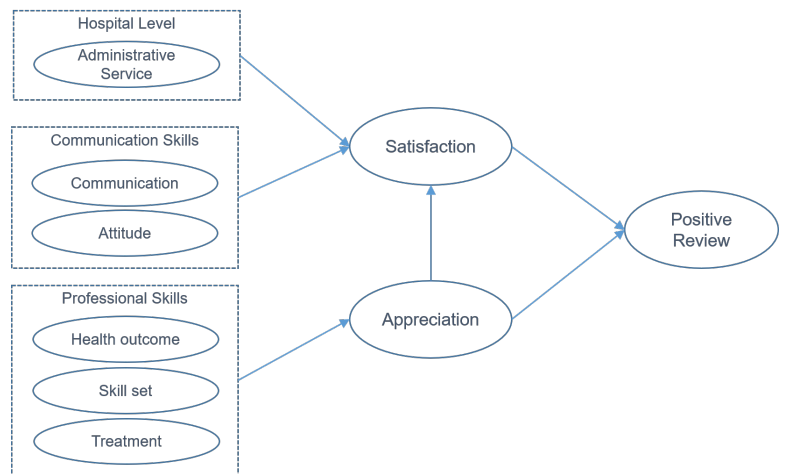

Figure 3a. Proposed model of positive $\mathrm{OHC}$ reviews

admission and administrative procedures. The quality of these services was mentioned in the results and the results show that it impacts how consumers write reviews. While we derive this theme from our data, it is also in agreement with the "logistics" factor defined in another research [22].

5.2.2 Communication Skills. This group captures the themes of reviews about the communication among doctors, patients and consumers. The quality of communication contributes to the doctor-patient relationship, which is crucial and important in modern medicine $[28,60]$. This relationship, no matter it is good or bad, has an impact on the health outcomes and therefore is reflected in the online reviews of doctors.

Two themes are included in this category: Communication and Attitude. Communication denotes whether the doctors convey, explain and elaborate the message clearly to patients and consumers. Doctors' skills of human communication play an important role in this perspective. Attitude refers to the doctors' attitude or posture towards patients and consumers. Some examples include patience, friendliness and fierce. Both themes had a high level of presence in our results.

5.2.3 Professional Skills. The category is comprised of three themes that are relevant to doctors' professional performance and the technical skills for diagnosing and treating patients: Health Outcome, Skill Set and Treatment.

Health Outcome indicates if the health condition has changed after the treatment, regardless of a positive or negative outcome. This is a common theme emerged from the data and is analogous to "technical quality" in [35]. As seen in the results, both positive and negative health outcomes after seeing a doctor attract reviews in either sentiment. Also illustrated in the content, reviewers hope the sharing of their health outcomes can help with other people with similar health conditions, and this information in fact is a type of eWOM that affects the decision of future health consumers. It

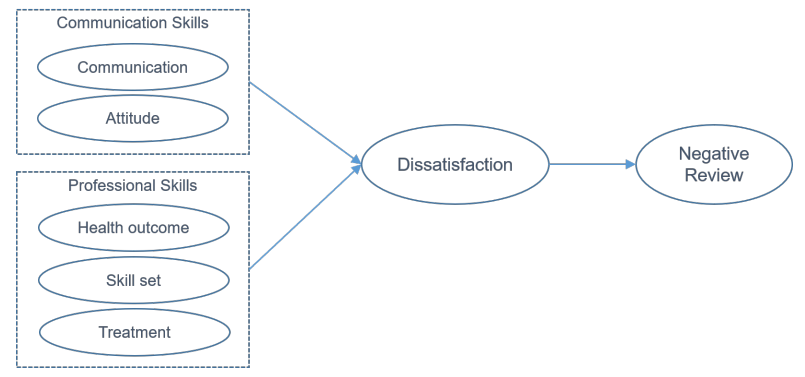

\section{Figure 3b. Proposed model of negative OHC} reviews

suggests that health outcome is the main driver of consumers posting online reviews in regard to their experience of seeing a doctor.

Skill Set is another theme appearing frequently in the reviews. By examining our dataset, we have found that it actually refers to different meanings, such as the quality of examination, the accuracy of diagnoses, the knowledge level of doctors, and the skills of carrying out operations. These are subjective perceptions based on the experience. We consider that Skill Set play an important part in the reviews, due to its frequent occurrence in the reviews.

Treatment is the last theme in this category. Our results have shown that doctors' reviews in fact reflect the complexity of the treatment, ranging from medication, injection, to surgery. A high number of reviews describe the experience of and after operations, which implies the increase in treatment complexity may lead to the writing of reviews.

\subsection{Proposed Model}

Based on the themes and qualitative analysis in our study, we propose the following model to describe the factors that lead to positive and negative reviews on OHC platforms (Figure 3a and 3b).

The initiators in our proposed model include the three categories of the six themes defined in Section 5.2. When patients and/or consumers encounter certain experience in their online consultation process, such experience turns into an intermediate sentiment, and finally trigger either positive or negative reviews. This model answers our second research question R2.

5.3.1 Positive Reviews. A positive experience of all factors in the model results in positive online reviews, but with a different intermediate sentiment. Good service at the hospital level and good communication skills lead to the consumers' satisfaction, which drives positive reviewing. According to our observations, merely good service or communication is not enough for 
people feeling grateful to their doctors, and therefore they do not lead to the status of appreciation.

When consumers are satisfied with the factors at the professional levels, for example, their health conditions become better or the treatment is successful, they feel appreciated and express their appreciation with positive reviews. We believe that appreciation is unique in the healthcare context and is rarely found in the reviews of other products. Although previous work points out that appreciation may be related to the Chinese culture [20, 22], we believe it shows that healthcare is not only a service, but also incorporating humanity, caring and compassion.

Our findings can be further explained with the Expectation Confirmation Theory (ECT) [40]. That is, as online reviews establish the initial expectations, health service consumers can relatively easily compare hospital's service, their doctor's communication skills and their treatment to the expectations. Hence, it is likely that they will be able to confirm their initial expectations and lead to satisfaction sentiments.

5.3.2 Negative Reviews. In our model, only the factors about communication and professional skills prompt negative reviews. For instance, factors like a doctor's arrogant attitude, an unsatisfactory treatment plan, or inadequate skill sets for a patient's health issues will result in dissatisfaction, which turns into negative reviews eventually. A recent study suggests that doctors with unprofessional behavior are more likely to create medical errors and complications after surgery [13]. We can imagine that such cases are very dissatisfactory and therefore consumers will let other people know about these issues using online negative reviews.

However, a negative experience in the services provided at the hospital level does not motivate dissatisfaction or negative reviews. For example, for a patient who waits for a long time for administrative paperwork, such a factor will not cause them to write negative reviews, unless there are other categories of factors involved. Our findings suggest that the factor of hospital services has a lower level of negative impact compared with other factors.

ECT can explain these associations. That is, for health service consumers, it is relatively hard to develop accurate initial expectations about and exactly measure the performance of their doctor's skill set and attitude as they are context specific. In this case, it is likely that consumers will disconfirm their initial expectations which then leads to dissatisfaction.

\subsection{Limitations and Future Research}

We acknowledge some limitations of this research. First, our dataset includes only one city in China and may not represent the patterns of the use of $\mathrm{OHC}$ in the entire nation. An analysis of datasets retrieved from multiple locations would be beneficial to address this issue. Future research should also test our model for other parts of the world, which have different cultural backgrounds and healthcare systems. Second, our study is based on the self-reported satisfaction levels of the review authors, and this may not reflect the sentiment of the content in some cases. Future studies may attempt to access objective data on satisfaction, such as the ongoing use of an OHC portal. Third, there might be significant differences between different diseases or health issues. For example, reviews related to serious illnesses, such as cancer, may be very different in nature from other health problems. Finally, the distribution of positive and negative reviews is skewed because Good Doctor Online has far more positive reviews than the negative ones. Future studies will need to account for the imbalance among types of reviews.

\section{Conclusion}

We present an analysis of the review content on a Chinese OHC platform in this paper. Using a mix of machine learning and qualitative analysis techniques, we have illustrated the topics and the themes derived from these reviews and propose a model for describing the factors motivating positive and negative reviews in the healthcare context. This work can be seen as an exploration of the conceptualization of information sharing using $\mathrm{OHC}$ reviews with different sentiments.

\section{Acknowledgement}

Our work was partially supported by a grant from the National Nature Science Foundation of China (Project No. 71701169) and the University of Melbourne MSE Early Career Research Grant 2019. We thank students Huizhe Luo and Kaiyuan Wu for their assistance.

\section{References}

[1] Alavi, M., and D.E. Leidner, "Review: Knowledge Management and Knowledge Management Systems: Conceptual Foundations and Research Issues", MIS Quarterly 25(1), 2001, pp. 107-136.

[2] Amblee, N., and T. Bui, "Harnessing the Influence of Social Proof in Online Shopping: The Effect of Electronic Word of Mouth on Sales of Digital Microproducts", International Journal of Electronic Commerce 16(2), 2011, pp. 91-114.

[3] Arnold, C.W., S.M. El-Saden, A.A.T. Bui, and R. Taira, "Clinical case-based retrieval using latent topic analysis", AMIA annual symposium proceedings, American Medical Informatics Association (2010), 26. 
[4] Biuk-Aghai, R.P., M. Yang, P.C.-I. Pang, W.H. Ao, S. Fong, and Y.-W. Si, "A map-like visualisation method based on liquid modelling”, Journal of Visual Languages \& Computing 31, Part A, 2015, pp. 87-103.

[5] Blei, D.M., "Probabilistic Topic Models", Commun. ACM 55(4), 2012, pp. 77-84.

[6] Blei, D.M., A.Y. Ng, and M.I. Jordan, "Latent Dirichlet Allocation", Journal of Machine Learning Research 3, 2003, pp. 993-1022.

[7] Braun, V., and V. Clarke, "Using thematic analysis in psychology", Qualitative Research in Psychology 3(2), 2006, pp. $77-101$.

[8] Cao, X., Y. Liu, Z. Zhu, J. Hu, and X. Chen, “Online selection of a physician by patients: Empirical study from elaboration likelihood perspective", Computers in Human Behavior 73, 2017, pp. 403-412.

[9] Cheema, A., and A. Kaikati, The Effect of Need for Uniqueness on Word Of Mouth, 2010.

[10] Cheung, C.M.K., and D.R. Thadani, "The impact of electronic word-of-mouth communication: A literature analysis and integrative model", Decision Support Systems 54(1), 2012, pp. 461-470.

[11] Cheung, M.Y., C. Luo, C.L. Sia, and H. Chen, "Credibility of Electronic Word-of-Mouth: Informational and Normative Determinants of On-Line Consumer Recommendations", International Journal of Electronic Commerce 13(4), 2009, pp. 9-38.

[12] Constant, D., S. Kiesler, and L. Sproull, "What's mine is ours, or is it? A study of attitudes about information sharing", Information systems research 5(4), 1994, pp. 400-421.

[13] Cooper, W.O., D.A. Spain, O. Guillamondegui, et al., "Association of Coworker Reports About Unprofessional Behavior by Surgeons With Surgical Complications in Their Patients", JAMA Surgery, 2019.

[14] Debortoli, S., O. Müller, I. Junglas, and J. vom Brocke, "Text Mining for Information Systems Researchers: An Annotated Topic Modeling Tutorial", Communications of the Association for Information Systems 39, 2016, pp. 110-135.

[15] Dellarocas, C., G. Gao, and R. Narayan, “Are Consumers More Likely to Contribute Online Reviews for Hit or Niche Products?”, J. Manage. Inf. Syst. 27(2), 2010, pp. 127-158.

[16] Dewan, S., Y.-J. (Ian) Ho, and J. Ramaprasad, "Popularity or Proximity: Characterizing the Nature of Social Influence in an Online Music Community", Information Systems Research 28(1), 2017, pp. 117-136.

[17] van Eck, P.S., W. Jager, and P.S.H. Leeflang, "Opinion Leaders' Role in Innovation Diffusion: A Simulation Study”, Journal of Product Innovation Management 28, 2011, pp. 187-203.

[18] Faraj, S., S. Kudaravalli, and M. Wasko, "Leading Collaboration in Online Communities", MIS Quarterly 39(2), 2015, pp. 393-411.

[19] Grimmer, J., “A Bayesian Hierarchical Topic Model for Political Texts: Measuring Expressed Agendas in Senate
Press Releases", Political Analysis 18(1), 2010, pp. 1-35.

[20] Hao, H., "The Development of Online Doctor Reviews in China: An Analysis of the Largest Online Doctor Review Website in China", J Med Internet Res 17(6), 2015, pp. e134.

[21] Hao, H., and K. Zhang, "The Voice of Chinese Health Consumers: A Text Mining Approach to Web-Based Physician Reviews", J Med Internet Res 18(5), 2016, pp. e108.

[22] Hao, H., K. Zhang, W. Wang, and G. Gao, "A tale of two countries: International comparison of online doctor reviews between China and the United States", International Journal of Medical Informatics 99, 2017, pp. 37-44.

[23] Hennig-Thurau, T., K.P. Gwinner, G. Walsh, and D.D. Gremler, "Electronic word-of-mouth via consumer-opinion platforms: What motivates consumers to articulate themselves on the Internet?", Journal of Interactive Marketing 18(1), 2004, pp. 38-52.

[24] Hong, L., and B.D. Davison, "Empirical Study of Topic Modeling in Twitter", Proceedings of the First Workshop on Social Media Analytics, ACM (2010), 80-88.

[25] Iyengar, R., C. Van den Bulte, and T.W. Valente, "Opinion Leadership and Social Contagion in New Product Diffusion”, Marketing Science 30(2), 2010, pp. 195-212.

[26] Jarvenpaa, S.L., and D.S. Staples, "The use of collaborative electronic media for information sharing: an exploratory study of determinants", The Journal of Strategic Information Systems 9(2), 2000, pp. 129-154.

[27] Karami, A., A.A. Dahl, G. Turner-McGrievy, H. Kharrazi, and G. Shaw, "Characterizing Diabetes, Diet, Exercise, and Obesity Comments on Twitter", International Journal of Information Management 38(1), 2018, pp. 1-6.

[28] Kelley, J.M., G. Kraft-Todd, L. Schapira, J. Kossowsky, and H. Riess, "The Influence of the Patient-Clinician Relationship on Healthcare Outcomes: A Systematic Review and Meta-Analysis of Randomized Controlled Trials", PLOS ONE 9(4), 2014, pp. e94207.

[29] Kolini, F., and L. Janczewski, "Clustering and Topic Modelling: A New Approach for Analysis of National Cyber Security Strategies", PACIS 2017 Proceedings, (2017), 126.

[30] Lederman, R., H. Fan, S. Smith, and S. Chang, "Who can you trust? Credibility assessment in online health forums", Health Policy and Technology 3(1), 2014, pp. 1325.

[31] Lee, J., and J. Kang, “A Study on Job Satisfaction Factors in Retention and Turnover Groups using Dominance Analysis and LDA Topic Modeling with Employee Reviews on Glassdoor.com”, ICIS 2017 Proceedings, (2017), 26.

[32] Lee, Y.-J., K. Hosanagar, and Y. Tan, "Do I Follow My Friends or the Crowd? Information Cascades in Online Movie Ratings", Management Science 61(9), 2015, pp. 2241-2258.

[33] Liu, J., J. Zheng, and W.U. Jiang, “An Empirical Research on the Factors Influencing the Selection of Doctors in Online Medical Websites", Journal of Medical Informatics 38(5), 2017, pp. 48-51. 
[34] Liu, Y., X. Zhang, J. Sun, Y. Jiang, and Z. Tian, "Understanding Patients' WOM of IT-Enabled Healthcare Service: A Case Study of Online Health Consultation", Proceedings of the 52nd Hawaii International Conference on System Sciences, (2019), 699-708.

[35] Lu, N., and H. Wu, "Exploring the impact of word-ofmouth about Physicians' service quality on patient choice based on online health communities", BMC Medical Informatics and Decision Making 16(1), 2016, pp. 151.

[36] Ma, B., H. Yuan, Y. Wan, Y. Qian, and N. Zhang, "Public Opinion Analysis Based on Probabilistic Topic Modeling and Deep Learning", PACIS 2016 Proceedings, (2016), 171.

[37] Ma, M., and R. Agarwal, "Through a Glass Darkly: Information Technology Design, Identity Verification, and Knowledge Contribution in Online Communities", Information Systems Research 18, 2007, pp. 42-67.

[38] National Health and Medical Research Council, and Consumers Health Forum of Australia, Statement on consumer and community involvement in health and medical research, 2016.

[39] Nunamaker Jr., J.F., and R.O. Briggs, "Toward a Broader Vision for Information Systems", ACM Trans. Manage. Inf. Syst. 2(4), 2012, pp. 20:1--20:12.

[40] Oliver, R.L., "A Cognitive Model of the Antecedents and Consequences of Satisfaction Decisions", Journal of Marketing Research 17(4), 1980, pp. 460-469.

[41] Pang, P.C.-I., and S. Chang, "The Twitter Adventure of \#MyHealthRecord: An Analysis of Different User Groups During the Opt-Out Period", Studies in Health Technology and Informatics 266, 2019, pp. 142-148.

[42] Pang, P.C.-I., S. Chang, J. Pearce, and K. Verspoor, "Online Health Information Seeking Behaviour: Understanding Different Search Approaches", Proceedings of the 18th Pacific Asia Conference on Information Systems (PACIS 2014), (2014).

[43] Pang, P.C.-I., S. Chang, K. Verspoor, and O. Clavisi, "The Use of Web-Based Technologies in Health Research Participation: Qualitative Study of Consumer and Researcher Experiences", Journal of Medical Internet Research 20(10), 2018, pp. e12094.

[44] Pang, P.C.-I., S. Chang, K. Verspoor, and J. Pearce, "Designing Health Websites Based on Users' Online Information Seeking Behaviours: A Mixed-method Observational Study", Journal of Medical Internet Research 18(6), 2016, pp. e145.

[45] Pang, P.C.-I., K. Verspoor, J. Pearce, and S. Chang, "Better Health Explorer: Designing for Health Information Seekers", Proceedings of the Annual Meeting of the Australian Special Interest Group for Computer Human Interaction (OzCHI'15), ACM Press (2015), 588-597.

[46] Park, C., and T.M. Lee, "Information direction, website reputation and eWOM effect: A moderating role of product type", Journal of Business Research 62(1), 2009, pp. 61-67.

[47] Park, D.-H., J. Lee, and I. Han, “The Effect of On-Line
Consumer Reviews on Consumer Purchasing Intention: The Moderating Role of Involvement", International Journal of Electronic Commerce 11(4), 2007, pp. 125-148.

[48] Pedregosa, F., G. Varoquaux, A. Gramfort, et al., "Scikit-learn: Machine Learning in Python", Journal of Machine Learning Research 12, 2011, pp. 2825-2830.

[49] Sen, S., T.S. Raghu, and A. Vinze, "Demand Information Sharing in Heterogeneous IT Services Environments", Journal of Management Information Systems 26(4), 2010, pp. 287-316.

[50] Strauss, A., and J. Corbin, "Grounded theory methodology", In Handbook of qualitative research. Sage Publications, Thousand Oaks, CA, 1994, 273-285.

[51] Strauss, A.L., and J.M. Corbin, Basics of Qualitative Research: Techniques and Procedures for Developing Grounded Theory, Thousand Oaks, CA, 1998.

[52] Sundaram, D.S., K. Mitra, and C. Webster, "Word-ofmouth communications: A motivational analysis", Advances in Consumer Research 25(1), 1998, pp. 527-531.

[53] Trusov, M., R. E. Bucklin, and K. Pauwels, "Effects of Word-of-Mouth Versus Traditional Marketing: Findings from an Internet Social Networking Site", Journal of Marketing 73(5), 2009, pp. 90-102.

[54] Urquhart, C., H. Lehmann, and M.D. Myers, "Putting the 'theory' back into grounded theory: guidelines for grounded theory studies in information systems", Information Systems Journal 20(4), 2010, pp. 357-381.

[55] Wang, C.A., X.M. Zhang, and I.-H. Hann, "Social bias in online product ratings: A quasi-experimental analysis", The Workshop on Information Systems Economics, (2010), $1-35$.

[56] Wang, C.A., X.M. Zhang, and I.-H. Hann, "Socially Nudged: A Quasi-Experimental Study of Friends' Social Influence in Online Product Ratings", Information Systems Research 29, 2018.

[57] Wenger, E., "Communities of practice: Learning as a social system”, Systems thinker 9(5), 1998, pp. 2-3.

[58] Wiesche, M., M.C. Jurisch, P.W. Yetton, and H. Krcmar, "Grounded theory methodology in information systems research”, MIS Quarterly 41(3), 2017, pp. 685-701.

[59] Wu, H., and N. Lu, "Service provision, pricing, and patient satisfaction in online health communities", International Journal of Medical Informatics 110, 2018, pp. 77-89.

[60] Zhang, X., X. Guo, K. Lai, and W. Yi, "How does online interactional unfairness matter for patient-doctor relationship quality in online health consultation? The contingencies of professional seniority and disease severity", European Journal of Information Systems 28(3), 2019, pp. 336-354

[61] Zifla, E., and S. Wattal, "What Doctors Wish They Knew: Treatment Compliance in an Online Health Community for Chronic Patients", Proceedings of the 52nd Hawaii International Conference on System Sciences, (2019). 